\title{
A monitoring network of the radioactive releases due to Garigliano nuclear power plant decommissioning
}

\author{
C. Sabbarese ${ }^{1}$, A.M. Esposito ${ }^{1}$, L. Visciano ${ }^{1}$, A. d'Onofrio ${ }^{1}$, C. Lubritto ${ }^{1}$, \\ F. Terrasi ${ }^{1}$, V. Roca ${ }^{2}$, S. Alfieri ${ }^{3}$ and G. Migliore ${ }^{3}$ \\ ${ }^{1}$ Dipartimento di Scienze Ambientali, Seconda Università di Napoli, Via Vivaldi, \\ 81100 Caserta, Italy, e-mail: Carlo.Sabbarese@unina2.it \\ ${ }^{2}$ Dipartimento di Scienze Fisiche, Università di Napoli "Federico II", Via Cintia, Napoli, Italy \\ ${ }^{3}$ Centrale Nucleare del Garigliano, SoGIN, Sessa Aurunca (Caserta), Italy
}

\begin{abstract}
The present study is the second part of a program of characterization of the site surrounding the SoGIN Garigliano Nuclear Power Plant (Southern Italy), which is currently involved in decommissioning activities. In the first phase of the project the reference groups of the population were established on the basis of a socio-economical study of the site; the radiological doses due to the assumed radioactive releases during the decommissioning phase were calculated by using climatological, hydrological, geomorphological parameters of the studied area; transport and diffusion specific models of some radionuclides in the environment were implemented to calculate the dose using specific evaluation software. The second part of the study focuses on the project of an environmental network designed in order to ensure the continuous monitoring of the radioactive release concentrations. All the criteria for the choice of grid points, by considering specific paths of transfer in the environment, were established for all the environmental compartments. A field campaign was carried out aiming to assess the "zero level" due to the natural radioactivity and past anthropogenic activities.
\end{abstract}

\section{INTRODUCTION}

Since several years, many nuclear installations in the world have been stopped because of the end of production lifetime, or for operation problems or, like in Italy, because the government decided that nuclear power will not be used. This stop created a new activity: decommissioning, also named restoration site, consisting in the dismantling of the nuclear installation with appropriate control and limitation of environmental and radiological impact which arise from these operations. The evaluation of risk and the actions to safeguard population are generally inspired to the recommendations of the International Commission on Radiological Protection (ICRP), but each country faces the problem with different evaluation methodologies and calculations [1]. That is due to the legislation differences and to different environmental, social and economical contexts where nuclear installations are located. For this, the decommissioning operations must be separately evaluated for each nuclear installation.

Our work carried out an evaluation of radiological impact of the decommissioning of the Nuclear Power Plant of Garigliano (Caserta, Italy). This Nuclear Power Plant, managed by SoGIN (Società di Gestione degli Impianti Nucleari), began its activity in 1964 by using a boiling water reactor with a production of $160 \mathrm{MW}$ electric power. Since 1979 this nuclear installation was stopped for maintenance and later no more used for the Italian government decision following the referendum in 1986. Now, the Nuclear Power Plant of Garigliano has the reactor isolated with respect to the remaining part and, all components and pipes have been drained and sealed. The underground tanks of radioactive wastes have been emptied and decontaminated. 
The decommissioning activities foresee radionuclide releases. The released activities will be much lower than during the working phase of the plant but, in any case, it can give a dose to the surrounding population. In order to monitor this dose to due to programmed and/or accidental radioactive releases, a research program has been started, whose aim is to evaluate the environmental impact of the decommissioning activities, and more specifically:

(i) The identification of the reference population groups more exposed to the effects of such activities;

(ii) The updating of the dose assessment calculation code (Vadosca) used till now by SoGIN and comparing the results with those obtained by means of other internationally validated codes;

(iii) The choice of the most adequate calculation code to evaluate environmental impact of the Garigliano Nuclear Power Plant activities in routine and accidental releases, taking into account the surrounding environmental characteristics.

(iv) The definition of a "zero level" of the natural and antropogenic radioactivity of the area around the NNP.

The research program will be carried out through several steps. Detailed results of the first part of this work are reported in [1]; the part of the study regarding monitoring network (iv) is the object of the present paper.

\section{METODOLOGY}

\subsection{Social and economical investigation}

The area around the NPP, object of the social and economical investigation, includes the territory inside a circle of $10 \mathrm{~km}$ radius and having centre in the NPP. The area has been divided in 16 angular sectors, numbered clockwise beginning from the North sector, and, also, in 20 concentric circles, equidistant between them $0.5 \mathrm{~km}$; in conclusion, the area turns out to be divided in 320 particles (Fig. 1). The investigation was carried out in the second quarter of 2001and its aim was to control and update the data of the demographic census by ISTAT in 1991 [3]. It has been tried to reconstruct the location of the built-up area and the alimentary typical habits of the population, in order to search possible variations of the reference groups, of the agricultural local productions and their distribution. We used questionnaires to evidence alimentary habits in prominence, since along the trophic chains one needs to search the possible sources of contamination from radionuclides.

\subsection{The environmental campaign}

On the basis of the grid points of the monitoring network of SoGIN's routine control, we planned an environmental special campaign by increasing the number of points and of the kind of measurements with the aim to establish the "zero level", i.e. the current level of radioactivity in the different environmental matrixes due to natural and antropogenic sources.

The basic criteria to plan grid points have been dictated from the knowledge of the meteorological conditions of the area, of the chemical-physical nature of the effluents, from the relation between conditions of atmospheric turbulence and morphology of the area (to foresee the path of the contaminants) and from the analyses of the indirect ways of contamination to the man. Among the data selected for the characterization of the site, the prevailing direction of the winds has allowed to add a selective criterium to the choice of the measurement points, privileging the places where farmhouses, farms or inhabited centres are located. 
In order to monitor and evaluate the transfer of the contamination from the land and fluvial environmental compartment to the biotic compartments (possible exposure of the reference groups), analyses of samples of the terrestrial and fluvial-sea compartments were planned. Along the principal way of diffusion of the wind, (angular sectors 2 and 10), where present, the analysis of the following vegetable matrixes was carried out: Vegetable to fruit, Vegetable to root, Fruit, Bovine meat, Bovine milk, Eggs, Ovine meat, Ovine Milk.

As far as the fluvial-sea compartments, fish, water and sediments have been sampled along the course of the river and at the mouth of the river.

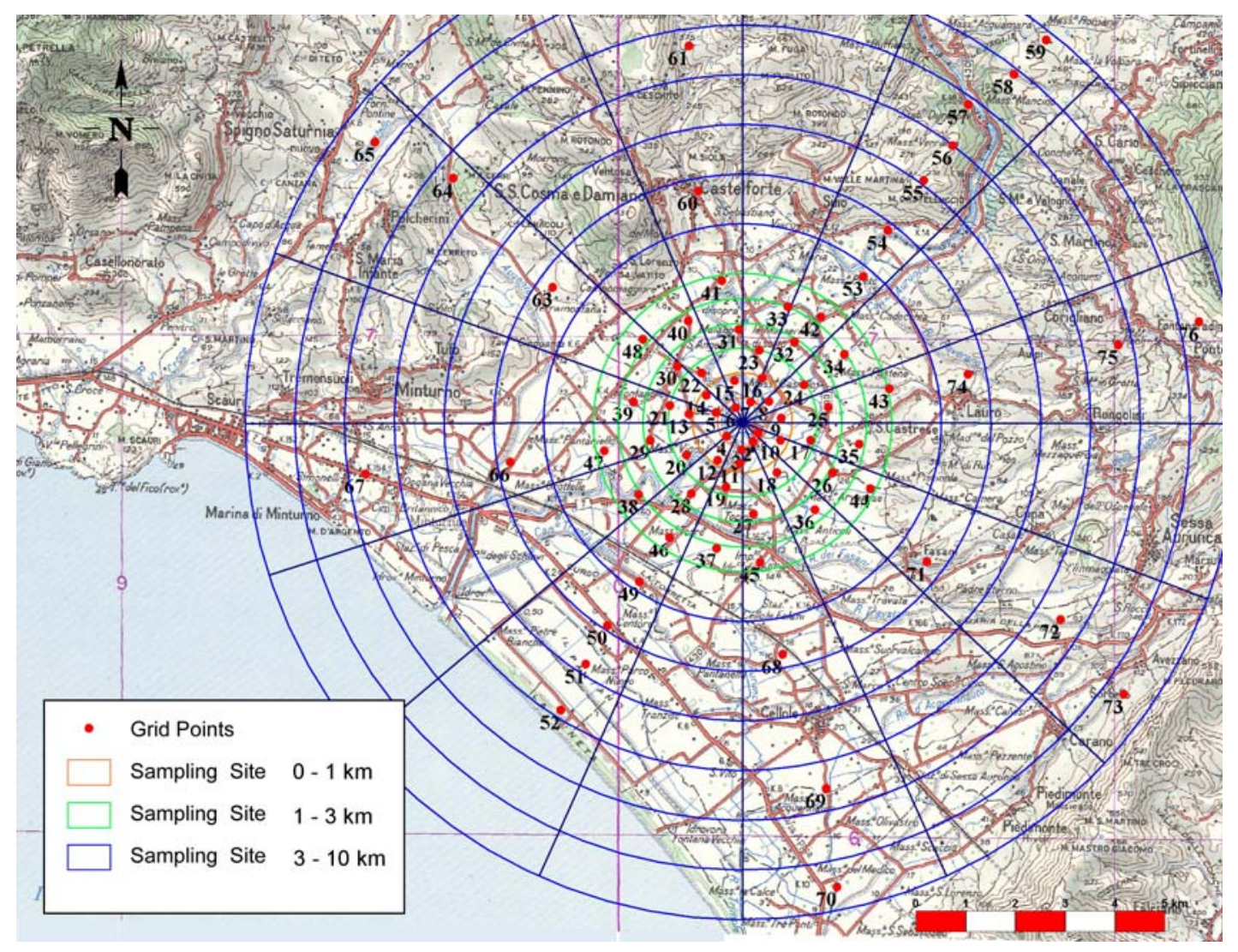

Figure 1. Studied area divided in 16 radial sectors and 13 circular crowns and map of the grid points of the environmental network.

The collection of soil samples for the evaluation of the environmental radioactivity of the area has been performed with a diversified density as a function of the distance from the plant. The area has been divided in three zones named A, B, C (see Fig. 1).

The soil samples have been collected along a vertical profile $30 \mathrm{~cm}$ deep. Analyses have been performed on three samples each one relative to $10 \mathrm{~cm}$ depth of soil. The determination of the radionuclides activities has been made by $\gamma$-ray spectrometry by using a high resolution HP Ge detector system with low background. The efficiency calibration curves and minimum detection activities (MDA) have been performed for each matrix-geometry system. 


\section{RESULTS AND DISCUSSION}

\subsection{Social and economical investigation and reference groups}

The Garigliano NPP is situated in an inlet of the course of the Garigliano river, about $7 \mathrm{~km}$ away from the Tyrrenian sea. The principal agricultural productions in the radius of $10 \mathrm{~km}$ are the orchards, the vegetables and the forage. The course of the Garigliano river divides the area under study in two parts: in the northern part the crops of cereals and forage in lowland and the grapevines in hill predominate; in the southern part the dominant crop in lowland is the vegetables, in hill the fruit trees. Also, zootechnique activity is diffused, with predominant breedings of cattle and buffalos.

The social and economic investigation has allowed to evaluate the data relative to the updated reference groups: Farmers and inhabitants with garden from 0 to $2 \mathrm{~km}$ from the NPP, Local population from 2 to $3 \mathrm{~km}$ from the NPP and Fishermen at the mouth of the Garigliano. For the first two groups we have studied both adults and children and, for each group, relative diet has been considered.

\subsection{Environmental network and definition of the "zero level"}

Mean values and range of the U-238, Th-232, K-40 and Cs-137 specific activities in soil samples are reported in Table I. The results of Co-60 specific activities are instead lower than the detection limit. ${ }^{137} \mathrm{Cs}$ specific activities isolevels are reported in fig.2. From the analysis of the results it can be concluded that the presence of traces of Cs-137 in the majority of the terrestrial samples is coherent with the radioactive atmospheric fallout. The activities of the U-238, Th-232 and K-40 display the geological nature of the area of volcanic origin. The results of the background gamma radiation dose range between 0.07 and $0.23 \mu \mathrm{Sv} / \mathrm{h}$ and the highest levels are in agreement with typical values of the volcanic area of the Roccamonfina volcano, where is also present grey tuff in surface; the lower values are located specially around the Garigliano bed where alluvional sediments are present. The map reported in Figure 3 and obtained from the GIS system by using an interpolation method displays the dose values interpolated in the entire area under study. On the basis of these results the dose mean value estimated for the population of the area is $0.16 \mu \mathrm{Sv} / \mathrm{h}$, to be compared with Italian volcanic areas mean values of $0.19 \mu \mathrm{Sv} / \mathrm{h}$.

No presence of ${ }^{137} \mathrm{Cs},{ }^{60} \mathrm{Co}$ and ${ }^{3} \mathrm{H}$ has been detected in groundwaters and fluvial waters.

Specific activities of ${ }^{137} \mathrm{Cs}$ and ${ }^{60} \mathrm{Co}$ ranging between 1 and $4 \mathrm{~Bq} / \mathrm{kg}$ have been detected in some fluvial sediment samples. In the fish and sand samples of river ${ }^{137} \mathrm{Cs}$ and ${ }^{60} \mathrm{Co}$ specific activities are lower than $1 \mathrm{~Bq} / \mathrm{kg}$. In the fish samples taken at mouth of the river ${ }^{137} \mathrm{Cs}$ is present with levels lower than $1 \mathrm{~Bq} / \mathrm{kg}$ and ${ }^{60} \mathrm{Co}$ is not detectable. Moreover, no contamination of artificial radionuclides has been detected in meat and milk (bovine and ovine), in vegetable and fruit of the studied area.

Table 1. Results of specific activities of considered radionuclides in soils.

\begin{tabular}{|l|c|c|c|c|}
\hline & \multicolumn{4}{|c|}{ Specific activity in soil (Bq/kg) } \\
\hline Radionuclide & ${ }^{238} \mathrm{U}$ & ${ }^{232} \mathrm{Th}$ & ${ }^{40} \mathrm{~K}$ & ${ }^{137} \mathrm{Cs}$ \\
\hline Mean value & 63 & 123 & 715 & 10 \\
\hline Range & $14 \div 114$ & $32 \div 865$ & $322 \div 1640$ & $1 \div 47$ \\
\hline
\end{tabular}



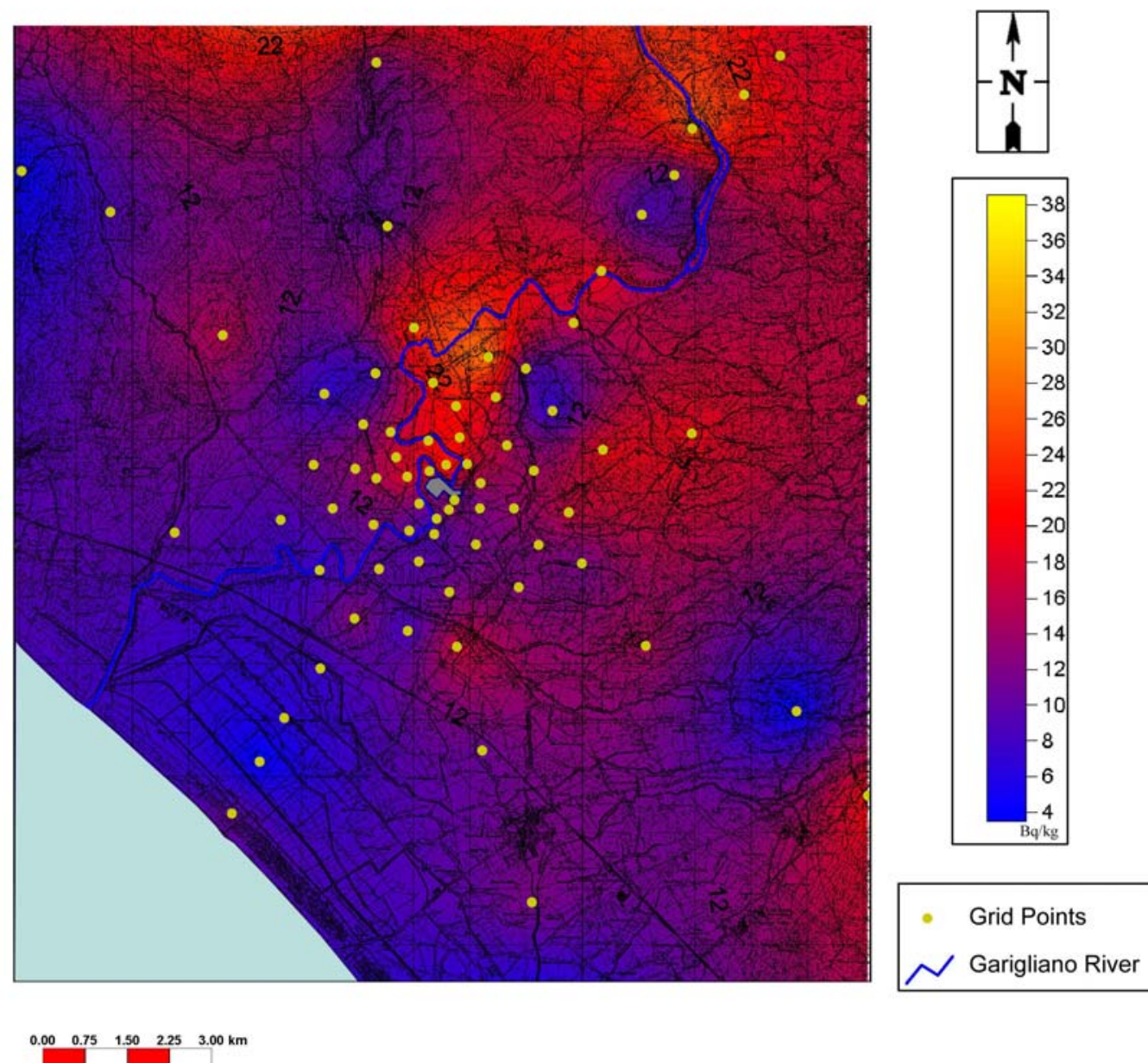

Figure 2. Isolevels of the ${ }^{137} \mathrm{Cs}$ concentrations in soils.

\section{CONCLUSIONS}

This work has allowed to get information on the environmental status of the area of Garigliano with respect to possible radiological impact with the definition of new reference groups. On the basis of this study the design and the realization of a campaign of measurements of environmental radioactivity was performed, which has interested many environmental matrixes to define the zero level of natural and antropogenic radioactivity.

This work is an example of applied radioecological study on contaminated sites focused on the project of a planned monitoring grid for all environmental compartments (i.e. atmospheric, marine, freshwater and terrestrial) that will be used during the decommissioning release activities, but it could also be the basis for developing new research activities regarding radionuclides transport and diffusion models or biological and physico-chemical techniques of restoration of polluted sites. 


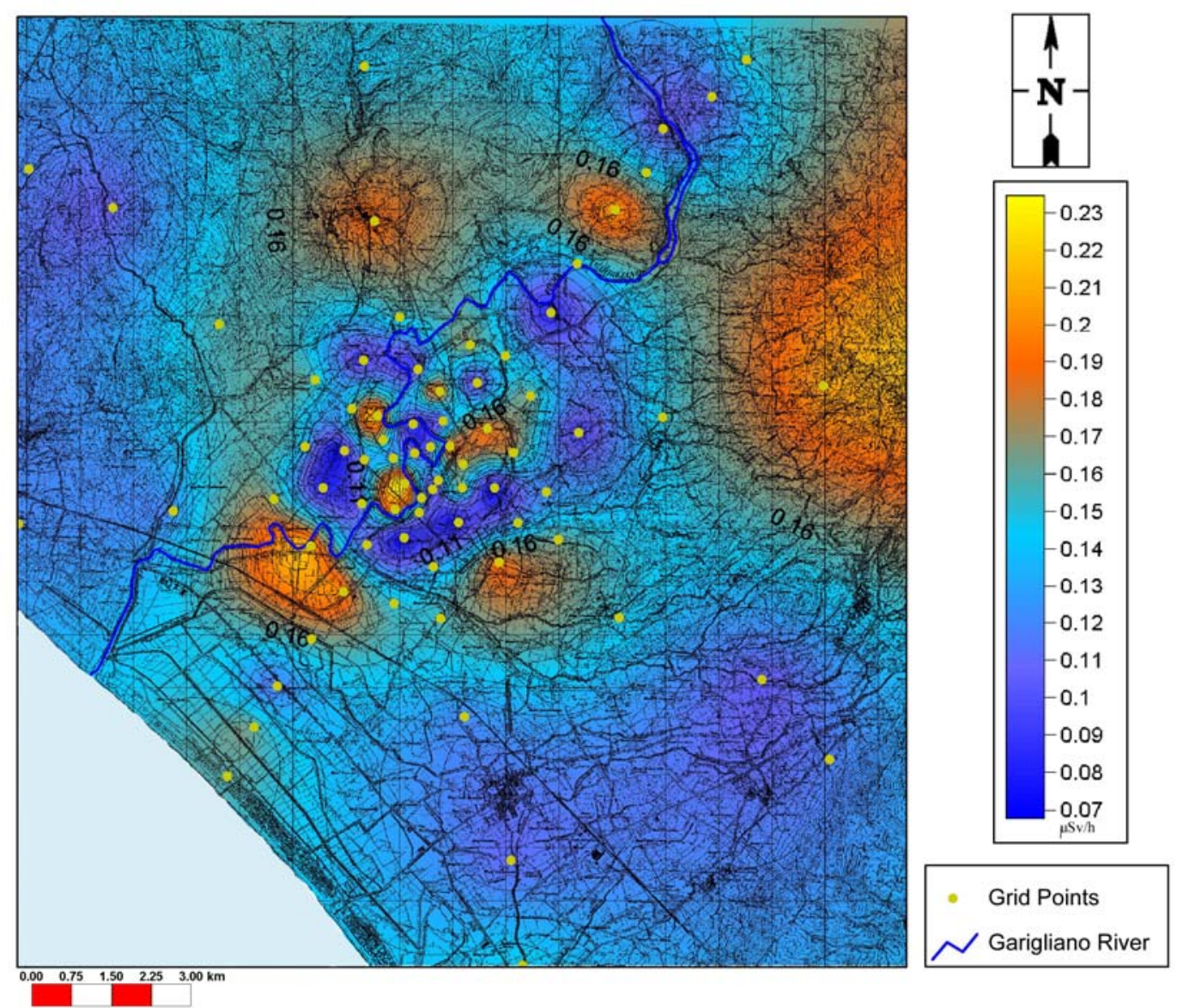

Figure 3. Isolevels of total $\gamma$-dose background.

\section{References}

[1] Simmonds, Lawson, Mayall "Methodology for assessing the radiological consequence of routine release of radionuclide to the environment" European Commission Radiation Protection 72, Report EUR 15760 EN; (1995).

[2] Esposito A.M., Sabbarese C., Sirignano C., Visciano L., D'Onofrio A., Lubritto C., Terrasi F., Alfieri S. and Migliore G.. Preliminary study of the environmental radiological assessment for the Garigliano Nuclear Power Plant decommissioning. In: Proceedings of the European IRPA Congress, Firenze 8-11 October 2002.

[3] ISTAT "Popolazione residente in Italia al 1 Gennaio 2000, per età, sesso e stato civile"; Report, (2000). 